\title{
3D CITYLUR: MODELLING 3D CITY LAND-USE REGULATIONS TO SUPPORT ISSUING A PLANNING PERMIT
}

\author{
S. Emamgholian ${ }^{1 *}$ J. Pouliot ${ }^{1}$, D. Shojaei ${ }^{2}$ \\ ${ }^{1}$ Dept. of Geomatics, Université Laval, Québec, Canada - saeid.emamgholian.1@ulaval.ca; jacynthe.pouliot@scg.ulaval.ca \\ ${ }^{2}$ Centre for SDIs and Land Administration, Department of Infrastructure Engineering, The University of Melbourne, Australia - \\ shojaeid@unimelb.edu.au
}

KEY WORDS: 3D Modelling, Land-use Regulation (LuR), Planning Permit, Information Modelling, City and Urban Planning

\begin{abstract}
:
The applications and understanding of Land-use Regulations (LuR) are more communicable when they are linked to the digital representation of the physical world. In order to support issuing a planning permit and move towards the establishment of automated planning permit checks, this paper investigates how LuRs related to a planning permit process can be modelled in 3D called 3D CityLuR. 3D CityLuR serves as a 3D model for representing LuRs' legal extents on a city scale. It is formed based on multiple geometric modelling approaches representing LuRs, which can provide a better cognitive understanding of LuRs and subsequently facilitate LuR automatic checks. To this purpose, according to LuRs' descriptions and characteristics explained in related planning documents, key parameters representing LuRs' extent are identified (e.g. maximum distance in overlooking or maximum allowed height in building height regulations). Accordingly, to automatically model each LuR, a geometric modelling approach (e.g. Boundary Representation (B-Rep), CSG, and extrusion) that best fits with the identified key parameters is proposed. In addition, to combine 3D CityLuR with an integrated BIM-GIS environment, the level of information need in terms of geometries and semantics is specified. Finally, the paper results in a showcase for five LuRs including building height, energy efficiency protection, overshadowing open space, overlooking, and noise impacts regulations. The showcase is a proof of concept for determining how these LuRs can be modelled in 3D and combined with 3D city models based on the selected geometric modelling approaches, identified parameters, and level of information need.
\end{abstract}

\section{INTRODUCTION}

\subsection{Context and Problematics}

Cities are overloaded with complex multilevel developments in small proximities, causing significant challenges for managing Land-use Regulations (LuR) related to use or developments on lands (Cann, 2018; Durham Jr and Scharffs, 2019; Selmi et al., 2017). The more densified cities become, the more difficulties planning authorities have of issuing planning permits. The problem is that while LuRs in a jurisdiction, theoretically, might have vertical dimensions, their spatial instantiation and graphical representation are mainly two-dimensional (2D) (Emamgholian et al., 2020a; Olsson et al., 2018). For example, in issuing planning permits, as shown in Figure 1(a), in Victoria, Australia, a proposed building façade including projections such as balconies should be set back from the side or rear boundaries not less than 1 meter, plus 0.3 meters for every meter of height over 3.6 meters up to 6.9 meters, plus 1 meter for every meter of height over 6.9 meters. Using 2D representation for verifying 3D LuRs like building setbacks, often requires significant experience and expertise to clarify the 3D dimensions of LuRs. In addition, it might cause significant shortcomings like uncertainty in decision-making especially in issuing planning permits and even cause erroneous permits (Emamgholian et al., 2020a; Van Berlo et al., 2013). In contrary, representing 3D LuRs like setbacks in 3D (Figure 1(b)), decreases ambiguities regarding its extents and facilitate the conflict detection process extensively (Emamgholian et al., 2020a; Faucher and Nivet, 2000).

\footnotetext{
Corresponding author
}

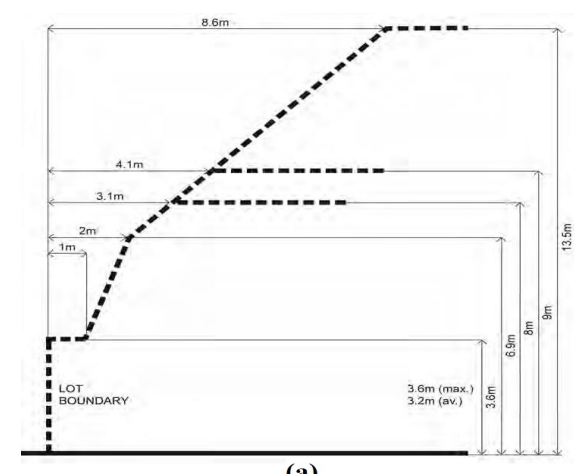

(a)

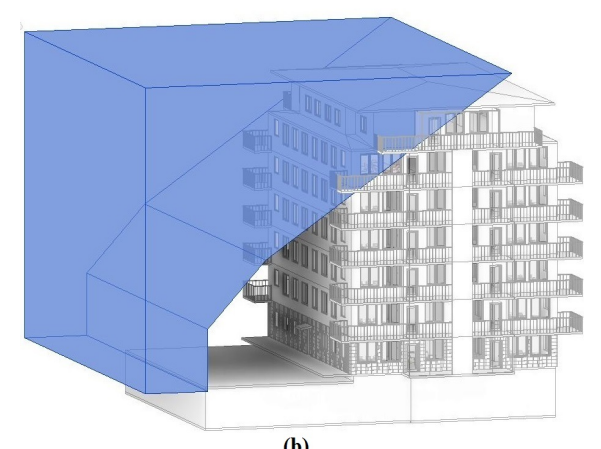

(b)

Figure 1. Setback regulation, a) in 2D (adapted from Melbourne Planning Scheme Ordinance, p. 1244); and b) modelled in $3 \mathrm{D}$ 
3D city models enable integrating various geospatial information related to issuing planning permits including proposed buildings (i.e. BIM in IFC format) and existing buildings (i.e. city data in CityGML format) into one system through 3D geo-virtual environments (Biljecki et al., 2015; Neuville et al., 2018). From the modelling point of view, the emphasis of 3D city model environments is on urban physical objects of a city such as building, relief (i.e. digital terrain model), city furniture, and transportation (Kolbe, 2009; Kolbe et al., 2020). 3D models and Building Information Modelling (BIM) can also be enriched with the representation of legal boundaries, and rights, restrictions, and responsibilities (RRR) in 3D digital cadastre (Atazadeh et al., 2017; Pouliot et al., 2018, 2016; Shojaei et al., 2018; Stoter et al., 2016).

The multi-dimensional nature of 3D city models with the capability of $3 \mathrm{D}$ analyses can also provide the ability to consider this environment for the representation of LuR extents in both statutory and strategic planning phases. In addition, intended users (e.g. lawyers, urban planners, urban specialists, and land surveyors), as well as the responsible authority for issuing planning permits (e.g. council), are more familiar with this environment rather than BIM which is more familiar for architects and building designers (Olsson et al., 2018).

\subsection{Objectives}

This study is part of a research project started in 2019 in collaboration between Laval University (Centre for Research in Geospatial Data and Intelligence) and the University of Melbourne (Centre for SDIs and Land Administration) to address the problem of detecting potential conflicts among 3D LuRs and physical objects. In the first phase of this project, the magnitude of potential LuR conflicts was classified into two classes as soft and hard conflicts. The 3D spatial configuration of LuRs referring to the shapes utilised to model LuRs was one of the prominent variables to classify the potential conflicts (see Emamgholian et al. (2020a)). Accordingly, as the second phase of this project, this paper aims to investigate how 3D LuRs related to the planning permit process can be modelled in 3D and then combined with an integrated BIM-GIS environment to support the conflict detection and issuing planning permit processes considerably.

To this purpose, for the modelling part, first, the key parameters of $3 \mathrm{D}$ LuRs are identified mainly from legal planning documents and then, a geometric modelling approach (e.g. BRep, CSG, extrusion) that best fits with the key parameters is proposed to model LuRs in 3D. The results of this stage called 3D CityLuR, which is a 3D model for representing LuRs on a city scale. It is formed based on multiple geometric modelling approaches representing LuRs, which can be used to validate proposed buildings against LuRs automatically in a later stage. For the combination part, the level of information need in terms of geometries and semantics are proposed with a focus on combining 3D CityLuR with an integrated BIM-GIS environment. The results create a linkage between LuRs and physical objects to support having a digital planning permit.

With this in mind, the next section provides a comprehensive review of the concepts underlying this study (e.g. geometric modelling approaches and level of information need). Section 3 presents the proposed approach, which is followed by implementing a 3D city model integrated with 3D CityLuR in Section 4 to showcase the feasibility of the proposed approach. The showcase realized as a proof of concept for determining how the LuRs related to the planning permit process can be modelled in 3D and combined with 3D city models. The final section concludes the article with the main findings and directions for future research.

\section{REVIEW OF CONCEPTS UNDERLYING THIS STUDY}

\subsection{Planning Permits in the City of Melbourne}

Since the LuRs foundation for managing land "use" and "development" varies between jurisdictions (Emamgholian et al., 2020a; Noardo et al., 2020), this paper focuses on a specific jurisdiction i.e. the state of Victoria, Australia. However, the proposed approach tries to be generic, and it can be applied to others if differences in terms of LuRs' descriptions are considered. According to Victoria's planning system ${ }^{1}$, a planning permit is "a legal document that allows a certain use or development to proceed on a specified parcel of land". Depending on the densification level of developments, city councils or the planning minister are the responsible authorities who issue planning permits mainly based on the planning scheme and its requirements.

The planning scheme is a legal document in which objectives, policies, and provisions related to the use, development, and protection of lands are indicated. It has several components such as zones, overlays, State Planning Policy Framework (SPPF), Local Planning Policy Framework (LPPF), particular provisions, general provisions, and schedules, and generally aims to regulate the "use" and "development" of land by planning regulations to make sure policies are met. It should be noted that based on Victorian definitions, a planning permit should not be confused with a "building permit" that will be issued based on the building codes considering the construction or alteration aspects of a building or development. This paper only considers LuRs related to issuing planning permits for building one, two or more dwellings on a lot, residential buildings, apartments with less than five storeys, and apartments containing five or more storeys.

\subsection{Geometric Modelling Approaches}

This section outlines the geometric modelling approaches that are the main focus of this paper. Generally, geometric modelling approaches can be categorized into two main groups including space-oriented and object-oriented for which there are different modelling approaches (Pouliot et al., 2006). In the space-oriented group (also called spatial occupancy enumeration) (e.g. voxel and octree), unlike the object-oriented group, usually, there are no holes left and everything in space is occupied. Implicit modelling resulting from a continuous mathematical representation by establishing a mathematical formula (Szeliski, 2010), can be linked with this group as well. However, explicit and object-oriented modelling that represents $3 \mathrm{D}$ objects by their constituent geometric elements with a fixed number of primitives (i.e. point, line, polygon, solid), are the focus of this study.

With this in mind, the modelling approaches in the objectoriented group (as the scope of this paper) mostly include wireframe (Ying et al., 2020), primitive instancing (De La Losa, 2000), Boundary representation (B-Rep) (Zlatanova, 2016), solid modelling (Knoth et al., 2020), Constructive Solid Geometry (CSG) (Jarroush and Even-Tzur, 2004; Knoth et al., 2020; Ying et al., 2020), sweeping (Knoth et al., 2020; Ying et al., 2020), and extrusion (Emamgholian et al., 2020b, 2017). Knoth et al. (2020), Ying et al. (2020), Ohori (2016), and Zlatanova (2016) have extensively reviewed different geometric modelling approaches such as B-rep, CSG, extrusion, and sweeping.

\footnotetext{
${ }^{1}$ https://www.planning.vic.gov.au/guide-home/using-victoriasplanning-system
} 


\subsection{Level of Information Need}

BIM and CityGML data use a multi-incremental Level of Development (LODev) $)^{2}$ and Level of Detail (LoD) number scale, respectively, to show the complexity of $3 \mathrm{D}$ models in different aspects such as geometries and semantics (i.e. 100 to 500 LODev in BIM, and 0 to 4 LoDs in CityGML v2) (Kolbe et al., 2005; Latiffi et al., 2015). Based on different applications, specific LODev and LoDs might be required to achieve a fitfor-purpose solution. For example, in issuing planning permits, for modelling LuRs in $3 \mathrm{D}$ and combining them with $3 \mathrm{D}$ city models, each LuR needs a specific LODev in the BIM design of a proposed building and a specific LoD in CityGML data of existing buildings (Emamgholian et al., 2020a). However, often by using the LODev/LoD concepts solely, planning authorities still need to check 3D models as well as planning maps and documents to make sure all the required information is included. Information requirements as "level of information need" and its concept and principles are discussed in EN ISO 19650 series with a focus on BIM. In addition, BS EN 17412-1 proposes a level of information need framework to define quality, quantity, and granularity of information requirements again in BIM. It discusses that based on different purposes, level of information need can vary in terms of geometrical information, alphanumeric information, and documentation.

In this paper, level of information need refers to both IFC/CityGML requirements and required planning information (e.g. zoning base map) to model LuRs automatically in the context of issuing planning permits. Taking overlooking regulation as an example, the window of a habitable room of a proposed building must not provide a direct line of sight to the windows of habitable rooms in existing buildings. As indicated in this example, although using LODev/LoD concepts might assure the existence or nonexistence of a window, it does not guarantee that the city data and BIM design distinguish habitable room windows from other windows. This point refers to the required information as level of information need.

\section{METHODOLOGY}

To achieve the objectives (section 1.2), an approach that mainly includes two stages is proposed. The two stages are: 1) modelling 3D LuRs (called 3D CityLuR) by defining their key parameters and selecting a geometric modelling approach for each $\mathrm{LuR}$, and 2) combining 3D CityLuR with $3 \mathrm{D}$ city models by determining the level of information need with a focus on geometric and semantic aspects of required information in $3 \mathrm{D}$ models and planning information as well as its linkage with LODevs/LoDs for proposed/existing buildings and city furniture. Although these two stages can be done simultaneously, in this paper, to have a better impression, they are explained separately.

\subsection{Modelling LuRs in 3D (3D CityLuR)}

Based on an updated version of the inventory proposed by Emamgholian et al., (2020a) in Victorian jurisdiction subject to the planning approval, table 1 shows thirteen identified 3D LuRs categorized into five groups. In this paper, five LuRs are selected (coloured in orange) to be modelled and further discussed. The selection is in a way that covers the applicability of different geometric modelling approaches including extrusion, B-rep, CSG, and sweeping for representing 3D

\footnotetext{
2 Acronym "LoDev" is used for Level of Development in BIMs to distinguish it from Level of Detail (LoD) in CityGML.
}

CityLuR as a 3D model using multiple geometric modelling approaches.

\begin{tabular}{|l|l|}
\hline Class & LuRs \\
\hline \multirow{4}{*}{ Zoning and dimensioning } & Building Height \\
\cline { 2 - 2 } & Side and Rear Setbacks \\
\cline { 2 - 2 } & Street Setbacks (Side and Front) \\
\cline { 2 - 2 } Overshadowing & North-facing Windows \\
\hline \multirow{3}{*}{ Daylight and Solar Access } & Energy Efficiency Protection \\
\cline { 2 - 2 } & Overshadowing Open Space \\
\hline \multirow{2}{*}{ Viewshed } & Daylight to Existing Windows \\
\hline \multirow{2}{*}{ Environmental } & Daylight to New Windows \\
\cline { 2 - 2 } & Overlooking \\
\hline
\end{tabular}

Table 1. Inventory of 3D LuRs and their categories (in orange, selected LuRs for tests)

3.1.1 LuR's Key Parameters: Parameters in this paper are any characteristics (e.g. dimensions) that are extracted from related documentations, plans, etc. as input information to enable the geometric modelling of LuRs automatically. Therefore, for defining 3D CityLuR's key parameters, after exploring each LuR extensively, based on their descriptions and characteristics, the key parameters were identified. Key parameters are required to automatically instantiate each LuR, and without them, the modelling phase fails. Since the modelling approach would be selected according to these parameters, they are called "key" parameters in this study. It should be noted that unselected LuRs in table 1 can be modelled similarly with differences in their key parameters. It should also be noted that although converting the LuRs' description to a machine-readable format is not the focus of this study, it can be applied in this stage to extract some of the key parameters automatically. The identified key parameters for the selected LuRs are discussed below.

Taking overlooking regulation as the first example, based on its description shown in Figure 2, four key parameters are identified including:

1) HDo: horizontal distance limit (i.e. 9 meters);

2) Wo: width of habitable room windows, balconies, terraces, decks, or patios of the proposed building;

3) RZo: rotation along the $Z$-axis; and

4) Ho: height of the window's floor level.

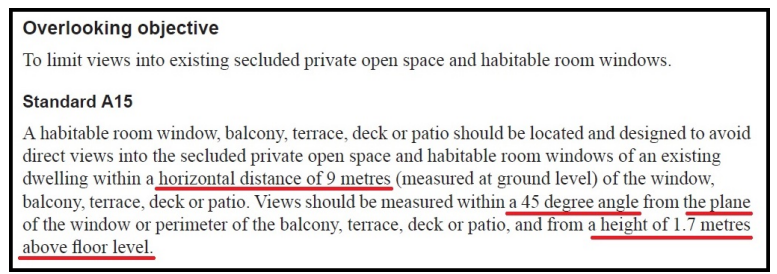

Figure 2. Overlooking description (adapted from Melbourne Planning Scheme Ordinance, clause 54.04-6)

By considering building height regulation, the vertical distance between ground level and the highest point in the proposed building should not exceed the maximum allowed height specified in a zone, schedule to the zone, or an overlay that applies to the land. Accordingly, two key parameters are identified for modelling building height regulation including:

1) Hb (i): height limits in each precinct based on height regulation; and 
2) Dhb (ij): planning zones' dimensions on the terrain.

Energy efficiency protection regulation considers the effect of overshadowing on an existing rooftop solar energy system on an adjoining lot. For overshadowing open space regulation, the overshadowing on existing secluded private open space will be checked. For both LuRs, the proposed building's shadow volume is required. For modelling shadow in $3 \mathrm{D}$, two parameters are identified including:

1) Psh (i): corner points of the proposed building's shadow on the terrain (or points of proposed building's shadow with a pre-defined threshold in more complex shadows); and

2) Pshb (i): related points of the proposed building façade causing a shadow on the terrain.

By considering noise impacts regulation, as the last LuR, residential buildings and dwellings near busy roads, railway lines, or industries should be designed in a way that limits noise levels in habitable rooms. The 3D impacts of noise depend on the noise sources (i.e. road, railway line, or industry) and their specified distances from the nearest trafficable lane/track in the planning scheme. Accordingly, two parameters are required to model this LuR including:

1) Dn (i): Affected distance; and

2) Ln (i): Length (of roads or railway lines).

3.1.2 LuRs' Geometric Modelling: Based on the identified key parameters of 3D LuRs, a geometric modelling approach that best fits with the identified parameters is proposed for each LuR. It should be noted that although modelling parameters may change in a specific case based on the LuR description in that area (e.g. setback limits are not the same for all precincts), the modelling approach and the procedure will remain the same. In addition, based on the scope of this paper, in this stage, we are not aiming to compare different modelling approaches, but to select one for each LuR based on their identified key parameters. That is why $3 \mathrm{D}$ CityLuR utilise multiple geometric modelling approaches to model 3D LuRs.

Taking overlooking regulation as an example, by considering its identified parameters (see Figure 2), it can be geometrically modelled by using the CSG approach in which a cylinder and a cuboid are combined by using intersect operator (Figure 3 ). Table 2 shows the dimensions of cylinder $(\mathrm{r}, \mathrm{h})$ and cube $(\mathrm{l}=\mathrm{w}$, h) based on its identified parameters (HDo, Wo, Ho).

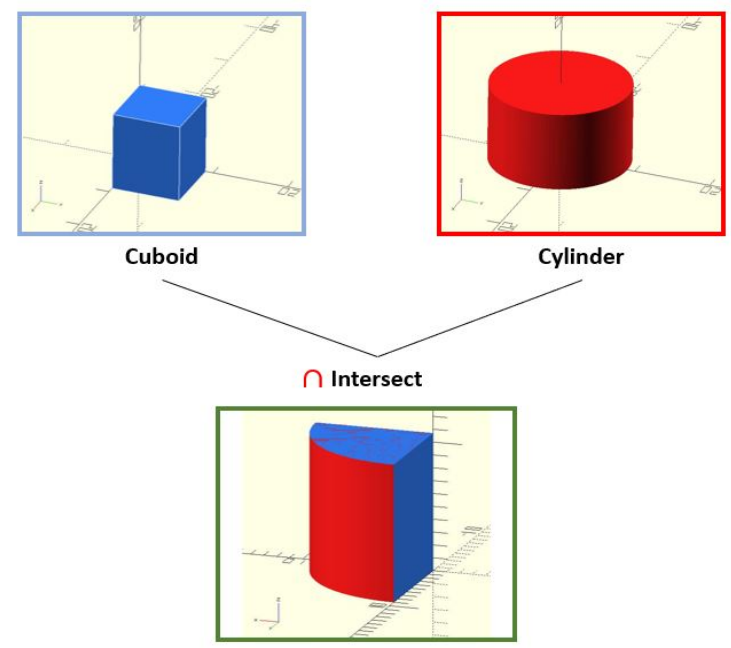

Figure 3. Modelling overlooking regulation using CSG

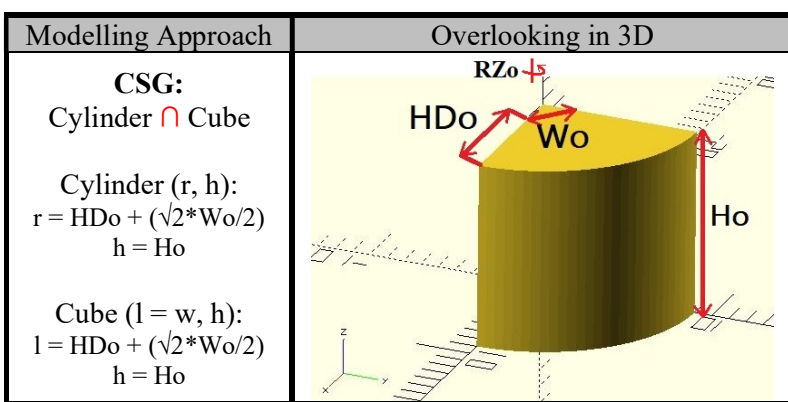

Table 2. Modelling overlooking LuR based on its identified parameters

By considering building height regulation and its identified parameters, it can be geometrically modelled by extruding $2 \mathrm{D}$ polygons of zoning base map using $\mathrm{Hb}$ values in each zone. Table 3 shows building height regulation in 3D with its identified parameters.

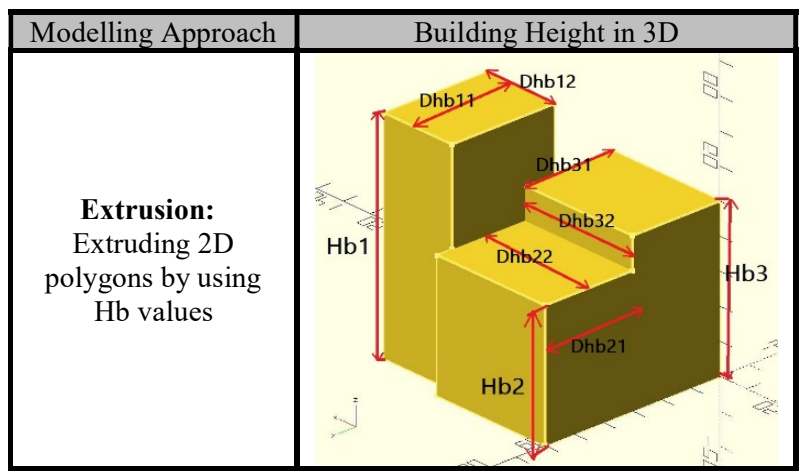

Table 3. Modelling building height LuR based on its identified parameters

For energy efficiency protection and overshadowing open space regulations, since their 3D extents vary based on the geometric shape and size of the proposed building, we propose to model it by using the B-Rep approach based on the identified parameters (i.e. Psh (i) and Pshb (i)). Table 4 shows energy efficiency protection and overshadowing open space regulations in $3 \mathrm{D}$ with its identified parameters. In section 4, the extraction of Pshb points using a reverse engineering method based on the notion of sun rays are discussed.

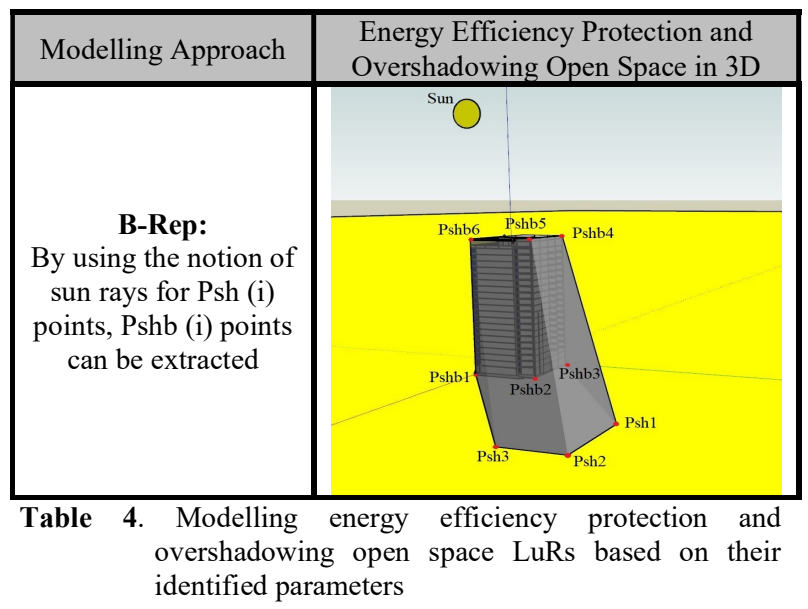


As the last LuR, for modelling noise impacts of roads and railway lines, a semicircle can be swept along the length of the paths or tracks. Table 5 shows noise impact regulation (e.g. for roads) in $3 \mathrm{D}$ with its identified parameters.

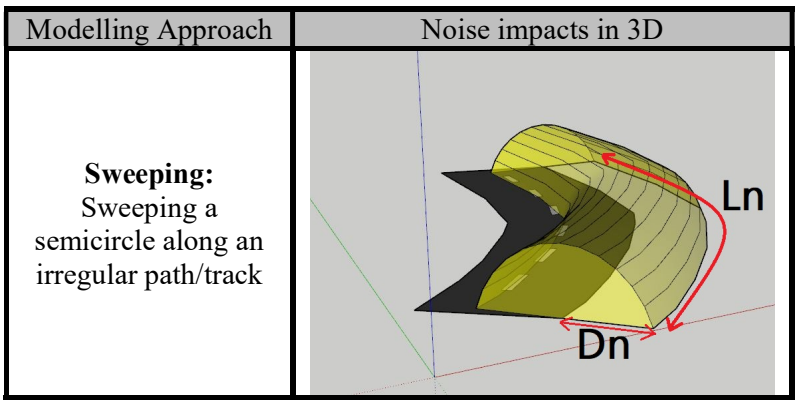

Table 5. Modelling noise impacts LuR based on its identified parameters

\subsection{Combining 3D CityLuR with 3D City Models}

After specifying modelling parameters of each LuR and selecting a suitable geometric modelling approach, 3D CityLuR should be combined with the 3D city model. Because of diversity of LuRs' characteristics and parameters and since each LuR might be geometrically modelled differently, 3D CityLuR is formed outside of 3D city models. Hence, 3D CityLuR also can be combined with any kind of 3D models. However, since CityGML and BIM are major trends in 3D modelling area, in this paper, a specific effort has been made to address the combination of 3D CityLuR with them. Therefore, in this paper, it is assumed that the 3D city model is an integrated BIM-GIS environment consisting of existing buildings in CityGML format and a proposed building model as BIM in IFC format. LODev in BIMs and LoD in 3D city models can vary based on different applications. In planning applications especially for issuing planning permits, they can significantly affect the process of modelling LuRs and combining them with 3D city models. However, since information requirements might not necessarily be linked with the LODev/LoDs in different applications and use-cases, specifying the required LODev/LoDs for 3D models cannot fully guarantee that the 3D CityLuR can be combined with 3D city models. For instance, planning information like zoning base map or some additional information might be required that is related to neither BIM LODev nor CityGML LoDs. Taking overlooking LuR as an example, in this case, access to specific geometries and semantics like a window, balcony, terrace, deck, and patio are required. This means an LODev 300 for BIM design of a proposed building is required. In addition, knowing some attributes like the function of windows (e.g. habitable room windows) is also required for modelling this LuR. The latter refers to the level of information need. Therefore, considering the level of information need and minimum required LODev/LoDs together is necessary to combine 3D CityLuR with the $3 \mathrm{D}$ city model successfully. In that regard, this stage defines the level of information need with a focus on required planning information and BIM/CityGML requirements as well as required IFC LODev/CityGML LoDs for the selected LuRs in order to combine 3D CityLuR with 3D city models ideally. This stage presents desired circumstances that assure the combination stage can be done automatically.

Table 6 shows the proposed level of information need and required LODev/LoDs for the selected LuRs that previously discussed. The level of information need considers both geometries and semantics (i.e. class of object and attributes) for modelling LuRs and combining them with the proposed building and existing buildings. It should be noted that in this paper temporal aspects of LuRs are not discussed thoroughly, and they are considered as part of attributes whenever is required (e.g. in overshadowing open space). It should also be noted that this stage does not discuss the conflict detection stage in which the information requirements differ. The next section presents a showcase as a proof of concept to demonstrate the feasibility of the proposed stages to model 3D LuRs and combine them with 3D city models by using CesiumJS 3D tiles.

\begin{tabular}{|c|c|c|c|c|c|}
\hline \multirow[b]{3}{*}{ LuR } & \multicolumn{3}{|c|}{ Required Information as Level of Information Need } & \multirow{2}{*}{\multicolumn{2}{|c|}{ Required LODev/LoDs }} \\
\hline & \multirow[b]{2}{*}{ Geometry } & \multicolumn{2}{|c|}{ Semantic } & & \\
\hline & & $\begin{array}{c}\text { Class of } \\
\text { Object }\end{array}$ & Attribute & $\begin{array}{c}\text { IFC } \\
\text { LODev } \\
\end{array}$ & $\begin{array}{l}\text { CityGML } \\
\text { LoD } \\
\end{array}$ \\
\hline $\begin{array}{l}\text { Building Height } \\
\text { Regulation }\end{array}$ & $\begin{array}{l}\text { Zoning base map (polygon) } \\
\text { geometries }\end{array}$ & - & $\begin{array}{l}\text { - Zones' category (road, port, capital } \\
\text { city, industrial, etc.) } \\
\text { - Height limit }\end{array}$ & $\begin{array}{l}\text { Not } \\
\text { required }\end{array}$ & $\begin{array}{l}\text { Not } \\
\text { required }\end{array}$ \\
\hline $\begin{array}{l}\text { Energy efficiency } \\
\text { protection }\end{array}$ & \multirow[t]{2}{*}{$\begin{array}{l}\text { 2D shadow (polygon) geometries of } \\
\text { proposed building on the terrain }\end{array}$} & - & $\begin{array}{l}\text { - Belongs to (proposed building/ } \\
\text { existing buildings) } \\
\text { - Dates and times (specified dates } \\
\text { and times in the planning scheme } \\
\text { for checking overshadowing) }\end{array}$ & \multirow[t]{2}{*}{300} & \multirow[t]{2}{*}{$\begin{array}{l}\text { Not } \\
\text { required }\end{array}$} \\
\hline $\begin{array}{l}\text { Overshadowing } \\
\text { Open Space }\end{array}$ & & \multicolumn{2}{|r|}{ Shadow } & & \\
\hline \multirow[b]{2}{*}{ Overlooking } & $\begin{array}{l}\text { Window geometries of proposed } \\
\text { buildings }\end{array}$ & Window & $\begin{array}{l}\text { - Function (habitable room, etc.) } \\
\text { - Floor Height }\end{array}$ & \multirow[b]{2}{*}{300} & \multirow{2}{*}{$\begin{array}{l}\text { Not } \\
\text { required }\end{array}$} \\
\hline & $\begin{array}{l}\text { Balcony/ Terrace/ Patio geometries } \\
\text { of proposed buildings }\end{array}$ & $\begin{array}{c}\text { Balcony/ } \\
\text { Terrace/ } \\
\text { Patio } \\
\end{array}$ & - Floor Height & & \\
\hline Noise impacts & $\begin{array}{l}\text { Street, railway line, and industry } \\
\text { geometries in zoning base map } \\
\text { surrounding proposed buildings }\end{array}$ & - & $\begin{array}{l}\text { - Name of road/ railway line/ } \\
\text { industry } \\
\text { - Category of road/ railway line }\end{array}$ & $\begin{array}{l}\text { Not } \\
\text { required }\end{array}$ & $\begin{array}{l}\text { Not } \\
\text { required }^{3}\end{array}$ \\
\hline
\end{tabular}

Table 6. Required planning information and LODev/LoDs for combining 3D CityLuR with the 3D city model

\footnotetext{
${ }^{3} \mathrm{LoD} 2$ is required whenever there is no street, railway line, and industry geometries in zoning base map surrounding proposed buildings
} 


\section{SHOWCASE}

The Showcase aims to demonstrate the feasibility of the twostage proposed approach for modelling LuRs in 3D and combining them with the $3 \mathrm{D}$ city model. In this showcase, planning authorities are the lead beneficiary of 3D CityLuR. This showcase, as a proof of concept, consists of programming inside a web-based application (i.e. Cesium) using JavaScript. In this stage, a sample high-rise building in IFC format (as the proposed building) converted to $3 \mathrm{D}$ tile format and imported to the Cesium ion. It should be noted that the BIM-GIS integration challenges (e.g., georeferencing BIM design, and converting IFC to $3 \mathrm{D}$ tile) are not addressed here, and we assume that this part is currently done by using software like FME to have a combined format as $3 \mathrm{D}$ tile which is suitable for visualizing and managing large datasets. The following notes demonstrate the results for the selected 3D LuRs including overlooking, building height, energy efficiency protection, overshadowing open space, and noise impacts regulations, respectively.

- Overlooking: For this LuR, the showcase only considers a habitable room of the proposed building. However, for other building elements (e.g. balcony and terrace) the process is quite similar. According to table 2, overlooking regulation was modelled using CSG by combining a cube and a cylinder using intersection operator (this part is done in OpenJSCAD). Moreover, the cylinder's dimensions ( $\mathrm{r}, \mathrm{h})$ as well as the cube's dimensions $(\mathrm{l}=\mathrm{w}, \mathrm{h})$ were calculated by having access to the window's width and floor height. Finally, according to table 6 , it was combined with the $3 \mathrm{D}$ city model by having access to the window of habitable room in the proposed building (Figure 4). Similarly, this process can be applied to all the habitable rooms windows.

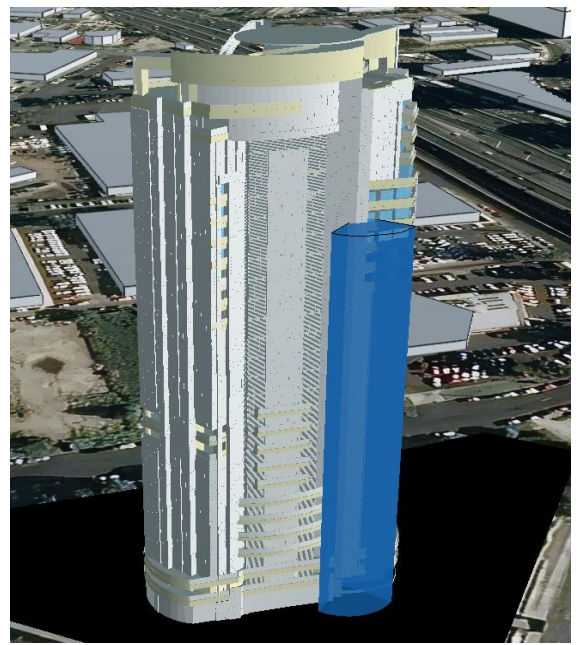

Figure 4. Overlooking regulation in 3D using CSG

- Building height: For modelling this LuR, 2D planning scheme zones, as zoning base map that is managed by the Department of Environment, Land, Water \& Planning $\left(\right.$ DELWP $\left.^{4}\right)$ was used for Fishermans Bend precinct (this zoning map is required according to the proposed level of information need in table 6). Based on zones' category (e.g. Capital City Zone) and height limits in each zone that have been added to the model as attributes, the Shapefile zoning map converted to GeoJSON and imported to Cesium ion (Figure 5(a)). As specified in table

\footnotetext{
${ }^{4}$ https://www.delwp.vic.gov.au/
}

3, an extrusion approach based on the height limit attributes was used to model this LuR in 3D as shown Figure 5(b).

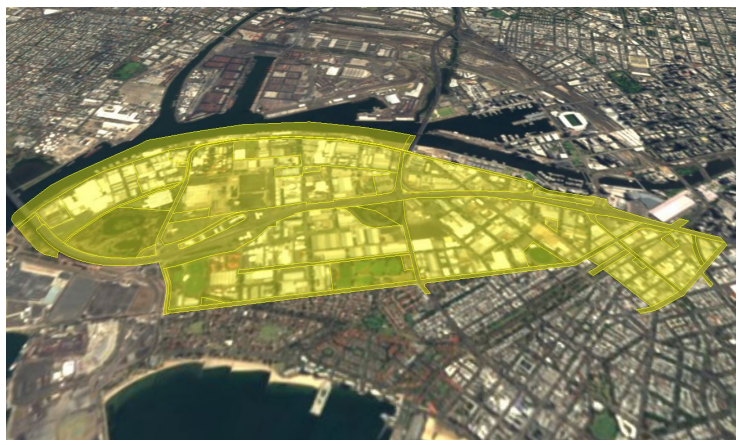

(a)

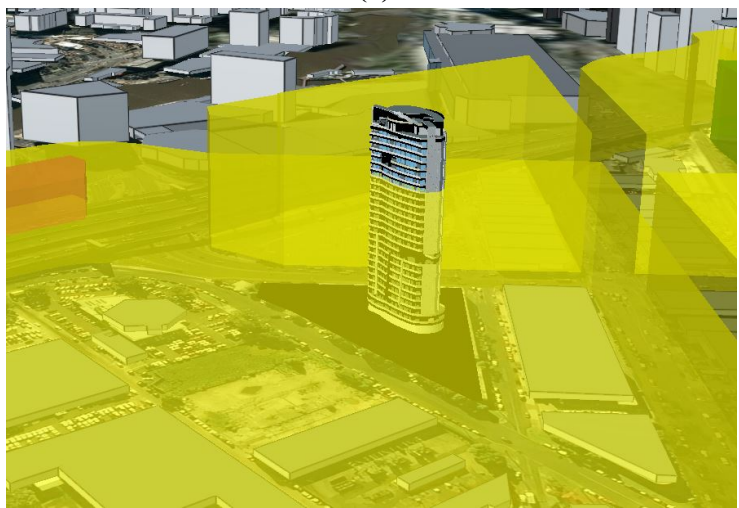

(b)

Figure 5. a) Part of zoning map in Fishermans Bend precinct; b) Building height regulation in $3 \mathrm{D}$ using extrusion

- Energy efficiency protection and overshadowing open space: Although the application of energy efficiency protection and overshadowing open space regulations is different, their modelling process is quite similar. Currently, available software and APIs mostly can model 2D shadows. By having access to the coordinates of corner points of the proposed building's shadow on the terrain and considering the sun's position (altitude: $\alpha$; azimuth: $z$ ) at the specified dates and times, these LuRs can be modelled in 3D using a reverse engineering method based on the notion of sun rays.

In this case, shadow points on the terrain serve as observer points that should be tracked along the sun's position to identify the top points. We used the position of the proposed building (e.g. the centre) for determining the oblique Distances (Di) for extracting the top shadow points of the proposed building. Figure 6(a) shows how from 2D shadow points, Di, $\alpha$, and $z$, other points' position can be extracted (i.e. red multiplication signs). After extracting top points for a specific time (e.g. $22^{\text {nd }}$ of September at 12:00 p.m. as one of the specified times for checking shadows in the planning scheme), by all the points including points of $2 \mathrm{D}$ shadow on the terrain and top points, the shadow volume can be modelled in $3 \mathrm{D}$ using B-Rep (Figure 6(b)).

Since in a later stage, we are aiming to detect potential conflicts between modelled overshadowing regulation with adjoining buildings, its overlap with the proposed building does not affect issuing planning permits. In addition, when the proposed building shape gets more complex, this method still can be applied and saves time and efforts. However, for having an accurate shadow in $3 \mathrm{D}$, extracting corresponding building geometries and shadow points is necessary. 


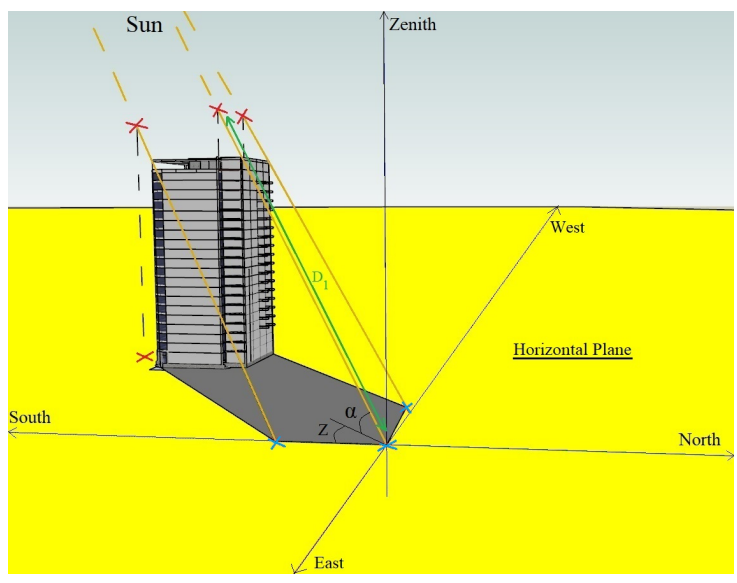

(a)

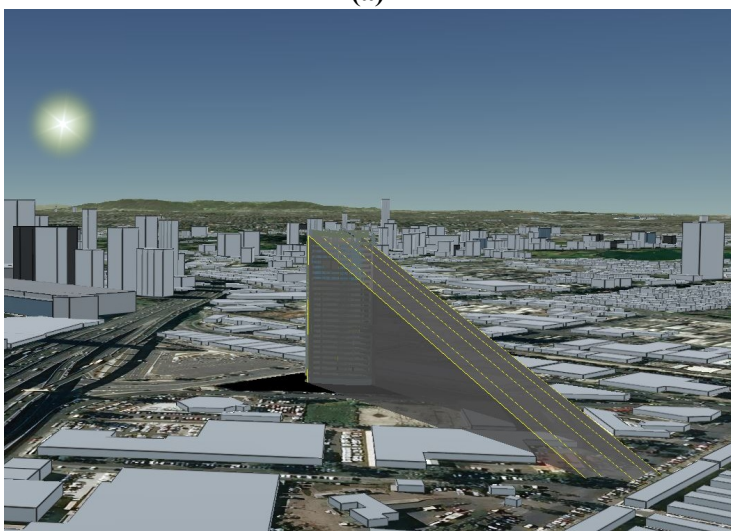

(b)

Figure 6. a) Extracted points (red multiplication signs) based on $\alpha$ (i), z (i), and D (i) for the 2D shadow points; b) Energy efficiency protection and overshadowing open space regulations in 3D using B-Rep

- Noise impacts: To model noise impacts in $3 \mathrm{D}$, a road zone in category 1 in Fishermans Bend was selected. According to Melbourne's planning scheme ordinance, the proposed building's construction materials need to be further checked if the proposed building is at less than 300 meters distance from the nearest lane of a freeway (Figure 7(a)). By considering this distance as Dn parameter (according to table 5), noise impacts regulation can be modelled and combined with the $3 \mathrm{D}$ city model by sweeping a semicircle (r: 300 ) along the road's path (Figure 7(b)). It should be noted for simplicity, noise impacts regulation is illustrated for a part of a freeway. However, the process is the same for other linear noise sources except for an industry for which a hemisphere can be used for modelling noise impacts regulation.

\begin{tabular}{l|l}
$\begin{array}{l}\text { Noise source } \\
\text { Zone interface }\end{array}$ & Noise influence area \\
\hline Industry & 300 metres from the Industrial 1,2 and 3 zone \\
\hline boundary
\end{tabular}

(a)

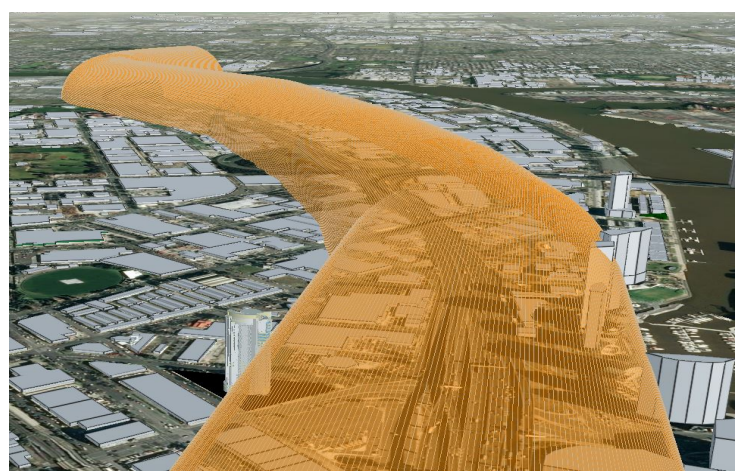

(b)

Figure 7. a) Noise influence area for different noise sources (adapted from Melbourne Planning Scheme Ordinance, p. 1281); b) noise impact regulation in 3D using sweeping

\section{CONCLUSION AND FUTURE STEPS}

This paper proposed a two-stage approach to model 3D LuRs extents as 3D CityLuR and combine it with $3 \mathrm{D}$ city models automatically to support the decision-making process in issuing planning permits. To our knowledge, the proposed approach is the first one extensively focusing on modelling LuRs in this field and as part of 3D city models.

In the first stage, key modelling parameters were extracted from legal notes of LuRs and accordingly, a geometric modelling approach that best fits with those parameters was proposed. As the main result of this stage, 3D CityLuR representing LuRs extents was formed automatically based on multiple proposed geometric modelling approaches. In the second stage, to combine 3D CityLuR with 3D city models automatically, the level of information need covering both required planning information and BIM/CityGML requirements in terms of geometries and semantics, as well as the required LODev/LoDs in proposed/existing buildings, were proposed. Without this stage, 3D CityLuR cannot be combined with 3D city models automatically. In addition, as an outcome, this stage makes the decision-making process shorter since planning authorities do not need to check 3D models as well as planning maps and documents to make sure all the required information is included. Moreover, it is a basis for a later stage which is to detect potential conflicts among 3D CityLuR and 3D city models to have a digital planning permit. After presenting the proposed approach, the paper resulted in a showcase for five LuRs including building height, energy efficiency protection, overshadowing open space, overlooking, and noise impacts. Although the planning permit process may vary in different jurisdictions, there are many similarities in general rules defining LuRs. Therefore, the proposed approach can be applied to others if differences in terms of LuRs' descriptions are considered. In addition, if there is no distinction between planning and building permit processes, it can still be applied to building regulations related to planning purposes.

As the commercialisation of digital planning/building permits increases in importance, integrating the concept of LuRs and automating their 3D representation gain more value in markets in the near future. We believe that it will also contribute to automatically detect potential conflicts between the proposed building, the existing buildings, and the LuRs in a later stage.

\section{ACKNOWLEDGEMENTS}

This project is funded by NSERC RGPIN-2015-05514 (JPouliot). The authors acknowledge the support of DELWP 
during this study. The authors emphasise that the views expressed in this paper are the authors' alone.

\section{REFERENCES}

Atazadeh, B., Kalantari, M., Rajabifard, A., Ho, S., 2017. Modelling building ownership boundaries within BIM environment: A case study in Victoria, Australia. Comput. Environ. Urban Syst. 61, 24-38.

Biljecki, F., Stoter, J., Ledoux, H., Zlatanova, S., Çöltekin, A., 2015. Applications of 3D city models: State of the art review. ISPRS Int. J. Geo-Information 4, 2842-2889.

Cann, D.M., 2018. The structure of municipal political ideology. State Local Gov. Rev. 50, 37-45.

De La Losa, A., 2000. Modélisation de la troisième dimension dans les bases de données géographiques.

Durham Jr, W.C., Scharffs, B.G., 2019. Law and religion: National, international, and comparative perspectives. Wolters Kluwer Law \& Business.

Emamgholian, S., Pouliot, J., Shojaei, D., 2020a. Modelling Land-Use Regulation Conflicts with 3D Components to Support Issuing a Building Permit, in: International Archives of the Photogrammetry, Remote Sensing and Spatial Information Sciences - ISPRS Archives.

Emamgholian, S., Taleai, M., Shojaei, D., 2020b. Exploring the applications of 3D proximity analysis in a 3D digital cadastre. Geo-Spatial Inf. Sci.

Emamgholian, S., Taleai, M., Shojaei, D., 2017. A novel approach for 3D neighbourhood analysis, in: International Archives of the Photogrammetry, Remote Sensing and Spatial Information Sciences - ISPRS Archives.

Faucher, D., Nivet, M.-L., 2000. Playing with design intents: integrating physical and urban constraints in CAD. Autom. Constr. 9, 93-105.

Jarroush, J., Even-Tzur, G., 2004. Constructive solid geometry as the basis of 3D future cadastre. FIG Work. Week, Athens, Greece.

Knoth, L., Atazadeh, B., Rajabifard, A., 2020. Developing a new framework based on solid models for 3D cadastres. Land use policy 92,104480 .

Kolbe, T.H., 2009. Representing and exchanging 3D city models with CityGML, in: 3D Geo-Information Sciences. Springer, pp. 15-31.

Kolbe, T.H., Gröger, G., Plümer, L., 2005. CityGML: Interoperable access to 3D city models, in: Geo-Information for Disaster Management. Springer, pp. 883-899.

Kolbe, T.H., Moshrefzadeh, M., Chaturvedi, K., Donaubauer, A., 2020. The Data Integration Challenge in Smart City Projects. Lehrstuhl für Geoinformatik.

Latiffi, A.A., Brahim, J., Mohd, S., Fathi, M.S., 2015. Building Information Modeling (BIM): Exploring Level of Development (LOD) in Construction Projects. Appl. Mech. Mater. 773-774, 933-937.
Neuville, R., Pouliot, J., Poux, F., De Rudder, L., Billen, R., 2018. A formalized 3D geovisualization illustrated to selectivity purpose of virtual 3D city model. ISPRS Int. J. Geo-Information 7, 194.

Noardo, F., Ellul, C., Harrie, L., Overland, I., Shariat, M., Arroyo Ohori, K., Stoter, J., 2020. Opportunities and challenges for GeoBIM in Europe: developing a building permits use-case to raise awareness and examine technical interoperability challenges. J. Spat. Sci. 65, 209-233.

Ohori, K.A., 2016. Higher-dimensional modelling of geographic information. Lulu. com.

Olsson, P.-O., Axelsson, J., Hooper, M., Harrie, L., 2018. Automation of building permission by integration of BIM and geospatial data. ISPRS Int. J. Geo-Information 7, 307.

Pouliot, J., Ellul, C., Hubert, F., Wang, C., Rajabifard, A., Kalantari, M., Shojaei, D., Atazadeh, B., Oosterom, P.J.M. van, De Vries, M., 2018. Visualization and new opportunities. Best Pract. 3D cadastres Ext. version.

Pouliot, J., Lachance, B., Kirkwood, D., 2006. L'importance de la modélisation géométrique 3D lors de l'élaboration d'un SIG 3D: Exemple du développement d'une structure topologique pour une application géologique. La Rev. Int. géomatique Inf. géographique tridimensionnelle 16, 29-49.

Pouliot, J., Wang, C., Hubert, F., Ellul, C., Rajabifard, A.R., 2016. 3D Cadastre visualization and dissemination: Most recent progresses and future directions, in: Proceedings of the 5th International FIG Workshop on 3D Cadastres. International Federation of Surveyors, FIG, pp. 337-359.

Selmi, D.P., Kushner, J.A., Ziegler, E.H., DiMento, J.F.C., Echeverria, J., 2017. Land use regulation: cases and materials. Wolters Kluwer Law \& Business.

Shojaei, D., Olfat, H., Rajabifard, A., Briffa, M., 2018. Design and development of a $3 \mathrm{D}$ digital cadastre visualization prototype. ISPRS Int. J. Geo-Information 7, 384.

Stoter, J., Ploeger, H., Roes, R., van der Riet, E., Biljecki, F., Ledoux, H., 2016. First 3D cadastral registration of multi-level ownerships rights in the Netherlands, in: Proceedings of the 5th International FIG 3D Cadastre Workshop, Athens, Greece. pp. $18-20$.

Szeliski, R., 2010. Computer vision: algorithms and applications. Springer Science \& Business Media.

Van Berlo, L., Dijkmans, T., Stoter, J.E., 2013. Experiment for inegrating Dutch 3D spatial planning and BIM for checking building permits, in: 8th 3DGeoInfo Conference \& WG II/2 Workshop, Istanbul, Turkey, 27-29 November 2013, ISPRS Archives Volume II-2/W1. ISPRS.

Ying, Y., Koeva, M.N., Kuffer, M., Zevenbergen, J.A., 2020. Urban 3D modelling methods: A state-of-the-art review. Int. Arch. Photogramm. Remote Sens. Spat. Inf. Sci. 43, 699-706.

Zlatanova, S., 2016. Representation: 3-D. Int. Encycl. Geogr. People, Earth, Environ. Technol. People, Earth, Environ. Technol. 1-27. 